potential explanations are incomplete B-cell depletion in relation to substantial surges in B-cell activating factor (BAFF). To improve B-cell targeting strategies, we conducted the first study in SLE patients aimed at investigating immunological effects and feasibility of combining rituximab (anti-CD20) and belimumab(anti-BAFF).

Methods Reported is the long-term follow-up of a phase 2 proof-of-concept study in 15 patients with SLE including 12 (80\%) with lupus nephritis (LN).

Results In 10/15(67\%) patients a clinical response was observed by achievement of lupus low disease activity state (LLDAS) of which $8(53 \%)$ continued treatment (belimumab $+\leq 7,5 \mathrm{mg}$ prednisolone) during the complete 2 years of follow-up. Five patients (33\%) were referred to as 'non-responders' due to persistent $\mathrm{LN}$, major flare or repeated minor flare. Out of $12 \mathrm{LN}$ patients $9(75 \%)$ showed a renal response including $8(67 \%)$ complete renal responders. All anti-dsDNA ${ }^{+-}$ patients converted to negative and both anti-C1q and extractable nuclear antigen autoantibodies (ENAs) showed significant reductions. $\mathrm{CD} 19^{+} \mathrm{B}$-cells showed a median decrease from baseline of $97 \%$ at 24 weeks, with a persistent reduction of $84 \%$ up to 104 weeks. When comparing responders to nonresponders, CD $20^{+} \mathrm{B}$-cells were depleted significantly less in non-responders and double negative (DN) B-cells repopulated significantly earlier.

Conclusion Combined B-cell targeted therapy with rituximab (RTX) and belimumab (BLM) prevented full B-cell repopulation including DN B-cells, with concomitant specific reduction of SLE-relevant autoantibodies. The observed clinical and immunological benefits in a therapy-refractory SLE population prompt further studies on RTX+BLM.

Acknowledgements This work is funded by the Dutch Kidney Foundation (KJPB12.028), Clinical Fellowship from the Netherlands Organization for Scientific Research (90713460) and GlaxoSmithKline (GSK) provided belimumab and an unrestricted grant for the clinical study.

\section{P128 EFFICACY OF INTRAVENOUS BELIMUMAB IN CHILDREN WITH SYSTEMIC LUPUS ERYTHEMATOSUS WITH MARKERS OF HIGH DISEASE ACTIVITY: ACROSS-TRIAL COMPARISON WITH ADULT BELIMUMAB STUDIES}

${ }^{1}$ Damon L Bass, ${ }^{2}$ Mohamed Okily, ${ }^{1}$ Anne Hammer, ${ }^{3}$ Beulah Ji, ${ }^{1}$ David Roth, ${ }^{4}$ Holly Quasny. 'GlaxoSmithKline, Collegeville, USA; ${ }^{2}$ GlaxoSmithKline, Uxbridge; ${ }^{3}$ GlaxoSmithKline, Stevenage, UK; ${ }^{4}$ GlaxoSmithKline, Research Triangle Park, USA

\subsection{6/lupus-2020-eurolupus. 172}

Background Belimumab is approved as add-on therapy for patients $\geq 5$ years with active, autoantibody-positive systemic lupus erythematosus (SLE). ${ }^{1}$ The PLUTO trial (NCT01649765) demonstrated safety and efficacy of belimumab in children with SLE $^{2}$ as generally consistent with adult studies. The current analysis assessed the efficacy of belimumab $10 \mathrm{mg} / \mathrm{kg}$ given intravenously (IV) to patient subgroups with baseline markers of high disease activity in PLUTO versus pooled BLISS-52 (NCT00424476) and BLISS-76 (NCT00410384) SLE trials.

Methods Patients 5-17 years (PLUTO) and $\geq 18$ years (BLISS-52 and BLISS-76) with active SLE were randomised to IV belimumab $10 \mathrm{mg} / \mathrm{kg}$ or placebo, plus standard of care (SoC) (PLUTO); ${ }^{2}$ and IV belimumab $10 \mathrm{mg} / \mathrm{kg}$, or
Abstract P128 Table 1 SRI4 response at Week 52 by subgroup for PLUTO and the pooled BLISS-52 and BLISS-76 studies (ITT population)

\begin{tabular}{llll}
\hline $\begin{array}{l}\text { PLUTO (paediatric; 5-17 } \\
\text { years) } \\
(\mathrm{N}=93)\end{array}$ & $\begin{array}{l}\text { BLISS-52 and BLISS-76 (adult; } \\
\geq 18 \text { years) } \\
(\mathrm{N}=1684)\end{array}$ \\
\hline $\begin{array}{llll}\text { Placebo } \\
(\mathrm{n}=40)\end{array}$ & $\begin{array}{l}\text { Bg IV } \\
(\mathrm{n}=53)\end{array}$ & $\begin{array}{l}\text { Placebo } \\
(\mathrm{n}=562)\end{array}$ & $\begin{array}{l}\text { Belimumab } 1 \mathrm{k}^{\dagger} \\
(\mathrm{n}=563)\end{array}$ \\
\hline
\end{tabular}

ITT population

$\mathrm{N}$

$39 \quad 53$

Response, $\mathrm{n}(\%)$

(43.6)

28 (52.8)

$562 \quad 563$

Difference, BEL vs

9.24

218

285 (50.6)

PBO, \%

$1.49(0.64,3.46)$

(38.8)

11.83

OR $(95 \% \mathrm{Cl})$

Baseline SELENA-SLEDAI score $\geq 10$

N

Response, n (\%)

$25 \quad 31$

$$
\begin{aligned}
& 12 \\
& (48.0)
\end{aligned}
$$

18 (58.1)

Difference, BEL vs

(48.0)

10.06

$\mathrm{PBO} \%$

$1.50(0.52,4.33)$

OR $(95 \% \mathrm{Cl})$

Baseline SELENA-SLEDAI score $\leq 9$

N

Response, $\mathrm{n}(\%)$

$14 \quad 22$

Difference, BEL vs

5 (35.7) $10(45.5)$

$\mathrm{PBO} \%$

9.74

$1.50(0.38,5.95)$

OR $(95 \% \mathrm{Cl})$

Baseline SELENA-SLEDAI score $\geq 13$

$\mathrm{N}$

Response, $\mathrm{n}(\%)$

$6 \quad 10$

Difference, BEL vs

$2(33.3) \quad 6(60.0)$

$\mathrm{PBO} \%$

26.67

OR $(95 \% \mathrm{Cl})$

Baseline SELENA-SLEDAI score $\leq 12$

N

Response, $\mathrm{n}(\%)$

$\begin{array}{ll}33 & 43 \\ 15 & 22(51.2)\end{array}$

Difference, BEL vs

(45.5)

$\mathrm{PBO} \%$

5.71

$1.26(0.51,3.12)$

OR $(95 \% \mathrm{Cl})$

Baseline anti-dsDNA $\geq 30 \mathrm{IU} / \mathrm{mL}^{*}$

N

Response, n (\%)

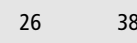

11
$(42.3)$

18 (47.4)

Difference, BEL vs

(4)

5.06

$\mathrm{PBO} \%$

$1.23(0.45,3.35)$

OR $(95 \% \mathrm{Cl})$

Baseline anti-dsDNA $<30 \mathrm{IU} / \mathrm{mL}^{*}$

N

Response, $\mathrm{n}$ (\%)

$13 \quad 15$

Difference, BEL vs

$6(46.2) \quad 10(66.7)$

$\mathrm{PBO} \%$

20.51

OR $(95 \% \mathrm{Cl})$

Baseline low C3 ${ }^{*}$

N

Response, $n$ (\%)

Difference, BEL vs

PBO,\%

$2.33(0.51,10.78)$

$\begin{array}{ll}299 & 296 \\ 132 & 187(63.2) \\ (44.1) & \\ & 19.03\end{array}$

$2.22(1.59,3.10)$

$263 \quad 267$

86 (32.7) 98 (36.7)

4.00

$1.16(0.81,1.67)$

$87 \quad 89$

$39(44.8) \quad 50(56.2)$

11.35

$1.63(0.89,3.00)$

OR $(95 \% \mathrm{Cl})$ 


\begin{tabular}{|c|c|c|c|c|}
\hline \multicolumn{5}{|c|}{ Baseline normal/high C3 ${ }^{*}$} \\
\hline N & 28 & 33 & 314 & 301 \\
\hline \multirow[t]{2}{*}{ Response, $\mathrm{n}(\%)$} & 14 & $21(63.6)$ & 139 & $152(50.5)$ \\
\hline & $(50.0)$ & & $(44.3)$ & \\
\hline Difference, BEL vs & & 13.64 & & 6.23 \\
\hline $\mathrm{PBO}, \%$ & & $1.75(0.63,4.88)$ & & $1.31(0.94,1.82)$ \\
\hline \multicolumn{5}{|l|}{ OR $(95 \% \mathrm{Cl})$} \\
\hline \multicolumn{5}{|l|}{ Baseline low $\mathrm{C}^{* \ddagger}$} \\
\hline $\mathrm{N}$ & 14 & 21 & 303 & 327 \\
\hline Response, n (\%) & $5(35.7)$ & $8(38.1)$ & $98(32.3)$ & $166(50.8)$ \\
\hline Difference, BEL vs & & 2.38 & & 18.42 \\
\hline $\mathrm{PBO}, \%$ & & $1.11(0.27,4.51)$ & & $2.45(1.74,3.45)$ \\
\hline \multicolumn{5}{|l|}{ OR $(95 \% \mathrm{Cl})$} \\
\hline \multicolumn{5}{|c|}{ Baseline normal/high C4 } \\
\hline $\mathrm{N}$ & 25 & 32 & 259 & 236 \\
\hline \multirow[t]{2}{*}{ Response, n (\%) } & 12 & $20(62.5)$ & 120 & $119(50.4)$ \\
\hline & $(48.0)$ & & $(46.3)$ & \\
\hline Difference, BEL vs & & 14.50 & & 4.09 \\
\hline $\mathrm{PBO}, \%$ & & $1.81(0.62,5.22)$ & & $1.19(0.82,1.72)$ \\
\hline \multicolumn{5}{|l|}{ OR $(95 \% \mathrm{Cl})$} \\
\hline \multicolumn{5}{|l|}{ Baseline steroids ${ }^{*}$} \\
\hline \multicolumn{5}{|l|}{ Yes } \\
\hline $\mathrm{N}$ & 37 & 50 & 488 & 478 \\
\hline \multirow[t]{2}{*}{ Response, $n$ (\%) } & 17 & $28(56.0)$ & 189 & $254(53.1)$ \\
\hline & (45.9) & & (38.7) & \\
\hline Difference, BEL vs & & 10.05 & & 14.41 \\
\hline $\mathrm{PBO}, \%$ & & $1.50(0.64,3.52)$ & & $1.86(1.42,2.42)$ \\
\hline \multicolumn{5}{|l|}{ OR $(95 \% \mathrm{Cl})$} \\
\hline \multicolumn{5}{|l|}{ No } \\
\hline $\mathrm{N}$ & 2 & 3 & 74 & 85 \\
\hline Response, n (\%) & $0(0)$ & $0(0)$ & $29(39.2)$ & $31(36.5)$ \\
\hline Difference, BEL vs & & 0 & & -2.72 \\
\hline $\mathrm{PBO}, \%$ & & - & & $0.91(0.47,1.76)$ \\
\hline OR $(95 \% \mathrm{Cl})$ & & & & \\
\hline
\end{tabular}

*Post hoc analyses; †Low C3 defined as $<90 \mathrm{mg} / \mathrm{dL}$; $¥$ low $\mathrm{C4}$ defined as $<10 \mathrm{mg} / \mathrm{dL}$ BEL, belimumab; C, complement; Cl, confidence interval; OR, odds ratio; PBO, placebo

placebo, plus SoC (BLISS trials). ${ }^{3}$ The primary endpoint was SLE Responder Index 4 (SRI4) at Week 52. This post hoc across-trial comparison (intention-to-treat [ITT] population) investigated the treatment effect of belimumab according to baseline disease activity indicators (Safety of Estrogens in Lupus Erythematosus National Assessment-SLE Disease Activity Index [SELENA-SLEDAI] score, anti-dsDNA and complement $\mathrm{C} 3 / \mathrm{C} 4$ levels) and steroid use; analyses were descriptive.

Results In PLUTO, belimumab demonstrated higher SRI4 response versus placebo; this response was similar for patients with baseline SELENA-SLEDAI scores of $\geq 10$ and $\leq 9$, and for and those receiving steroids, but greater in those with scores $\geq 13$, low anti-dsDNA, or normal/high C3/C4 (table 1). Subgroup analyses from the BLISS adult studies demonstrated similar findings with the exception of patients with high antidsDNA or low C3/C4 (table 1).

Conclusions Subgroup analyses from the PLUTO trial demonstrated favourable belimumab responses in paediatric patients with high SELENA-SLEDAI scores, similar to those observed in adult belimumab studies. However, these results should be interpreted with caution due to the small sample size of PLUTO, the post hoc nature of the analyses and other limitations.
Disclosures DLB, MO, AH, BJ, DR and HQ are employees of GSK. BJ and DLB hold stocks and shares in GSK; MO, AH, DR and HQ hold shares in GSK.

Acknowledgements This study was funded by GSK. Medical writing support was provided by Gosia Carless, PhD, Fishawack Indicia Ltd, UK, and was funded by GSK.

\section{REFERENCES}

1. Benlysta US prescribing information. GlaxoSmithKline; 2018. Available at: https:// www.gsksource.com/pharma/content/dam/GlaxoSmithKline/US/en/Prescribing_Information/Benlysta/pdf/BENLYSTA-PI-MG-IFU-COMBINED.PDF

2. Brunner H.I., Abud-Mendoza C., Viola D.I., Calvo I., Levy D.M., Calderon Gallegos J., et al. Efficacy and safety of intravenous belimumab in children with systemic lupus erythematosus. Arthritis Rheumatol 2018;70(59):3224-3225, Abstract 2867.

3. van Vollenhoven R.F., Petri M.A., Cervera R., Roth D.A., Ji B.N., Kleoudis, et al. Belimumab in the treatment of systemic lupus erythematosus: high disease activity predictors of response. Ann Rheum Dis 2012; 71:1343-1349.

\section{P129 ADOPTIVE TRANSFER OF AUTOLOGOUS CYTOTOXIC T LYMPHOCYTES AGAINST EPSTEIN-BARR VIRUS (EBV- CTL) IN PATIENTS WITH SYSTEMIC LUPUS (SLE): PRELIMINARY RESULTS}

${ }^{1}$ Antoine Enfrein, ${ }^{2}$ Béatrice Clémenceau, ${ }^{3}$ Soraya Saiagh, ${ }^{2}$ Henri Vié, 'Mohamed Hamidou. ${ }^{1}$ Service de Médecine Interne, CHU de Nantes, Nantes; ${ }^{2}$ INSERM, CRCINA, CHU Nantes; ${ }^{3}$ UTCG, CHU de Nantes, Nantes, France

10.1136/lupus-2020-eurolupus. 173

Background Patients with SLE show insufficient EBV control with an increased viral load and a decreased cytotoxic T-cell response associated with an abnormal humoral responses which theoretically may be pathogenic. In the present study we proposed an adoptive transfer of EBV-CTL to try to restore patients EBV specific T-cell control, and assess its effect on the humoral responses and the clinical status.

Methods Nine patients with SLE were enrolled in a Phase I/II clinical trial to receive autologous EBV-CTL $\left(5.10^{6}\right.$ cells $\left./ \mathrm{kg}\right)$. The frequency of EBV-specific T cells before and 10 days after injection was evaluated i) by ELISPOT directly on the peripheral blood mononuclear cells and ii) by estimation of IFN- $\gamma$, IL-2, TNF- $\alpha$ production and CD107 expression after preamplification of the EBV-specific precursors in vitro. We also monitored anti-VCA, anti-EAD, and anti-EBNA antibodies titers, EBV viral load, and clinical and biological disease activity parameters.

Results To date, 6 patients received EBV-CTL treatment. Ten days after injection, the EBV-CTL frequencies observed by ELISPOT increased moderately for 2 out of 3 patients tested. On the pre-amplified cells, increase in the production of IFN$\gamma$ after BLCL stimulation was observed for 4 out of 6 patients, and in the CD107 expression for 3 out of 6 patients. Serology titers remained stable during follow-up, with the exception of the anti-EBNA and anti-VCA IgG titers, which decreased in one patient. The viral EBV blood load did not vary significantly.

Conclusions The administration of EBV-CTL seems safe and well tolerated in SLE patients. Yet it might not be sufficient to improve the control of the virus by the host (and modify humoral response against EBV) despite a discreet increase in the EBV specific T-cell repertoire after injection. More data still need to be collected to precise the effects of the treatment on anti-EBV response and disease activity. 